\title{
Effect of Titanium Carbide Precipitates on the Ductility of 30 mass\% Chromium Ferritic Steels
}

\author{
Tadashi Fukuda \\ Institute for Materials Research, Tohoku University, Sendai 980-8577, Japan
}

\begin{abstract}
The effect of morphology of Ti carbides on the ductility of 30 mass $\% \mathrm{Cr}$ ferritic steels containing $\mathrm{C}$ and Ti was investigated by tensile test at low temperatures. $\mathrm{C}$ and $\mathrm{Ti}$ contents were varied from 0.011 to $0.071 \mathrm{mass} \%$, and from 0.094 to 0.60 mass $\%$, respectively. The ratio Ti/C was about nine. Two kinds of heat treatments were adopted to obtain different types of morphology of Ti carbide precipitates, namely numerous fine grain boundary Ti carbide precipitates about $0.05 \mu \mathrm{m}$ in diameter and coarse globular Ti carbide particles in the $1.5 \mu \mathrm{m}$ size range. The tensile ductility was evaluated by transition temperatures in reduction of area. The numerous fine grain boundary Ti carbide precipitates lead to an increase in the transition temperature more than uniformly dispersed coarse globular Ti carbide particles. The former brings about the increase in the amount of intergranularly fractured surface in dimple and brittle fracture more than the latter. Cluster-like coarse globular Ti carbides at grain boundaries cause a scatter band of the transition temperature. Microfractographic examinations reveal that initiation of microcracks for brittle fracture is considered to be caused by intergranular fracture cracks which are promoted by decohesion at the interface between the matrix and many grain boundary Ti carbide precipitates and by decohesion at the interface between the matrix and cluster-like coarse globular Ti carbides at grain boundaries.
\end{abstract}

(Received January 14, 2003; Accepted April 14, 2003)

Keywords: high chromium ferritic steels, ductility, titanium carbides, grain boundary precipitates, cluster-like carbides, transition temperature

\section{Introduction}

In $\mathrm{Fe}-\mathrm{Cr}$ alloys, it is known that impurity elements such as $\mathrm{C}$ and $\mathrm{N}$ are responsible for the decrease of toughness and ductility. ${ }^{1-4)}$ The variation in the degree of the embrittlement associated with heat treatments such as water quenching, air cooling and furnace cooling has been related to the amount of carbide and nitride precipitates. ${ }^{5,6)}$

In the previous papers, the author reported that an increase in the volume fraction of carbide and nitride precipitates resulted in an increase in the ductile-brittle transition temperature (DBTT) determined by impact tests and a decrease in the strain at fracture in tensile test, ${ }^{7)}$ and also reported that the DBTTs for reduction of area (RA) determined by tensile tests depended on the volume and morphology of $\mathrm{Cr}$ carbide and $\mathrm{Cr}$ nitride precipitates. ${ }^{8,9)}$ That is, $\mathrm{Cr}$ carbide, $\mathrm{Cr}$ nitride and $\mathrm{Ti}$ carbide precipitates at grain boundaries lead to more remarkable increase in the DBTT for RA than those precipitate particles within the grains. Fine spheroidal $\mathrm{Cr}$ carbide, $\mathrm{Cr}$ nitride and $\mathrm{Ti}$ carbide particles within the grains do not exert a significant detrimental effect on the DBTT for RA.

The purpose of the present study is to clarify the effects of the morphology of Ti carbide precipitates on the DBTT for $\mathrm{RA}$, fracture mode, and brittle fracture mechanism in tensile tests.

\section{Experimental Procedure}

Four $4 \mathrm{~kg}$ heats of $\mathrm{Fe}-30 \% \mathrm{Cr}$ alloys were melted from electrolytic iron and electrolytic chromium by a high frequency vacuum induction furnace. In order to obtain specimens containing different $\mathrm{C}$ and $\mathrm{Ti}$ contents, different amounts of $\mathrm{Fe}-4 \% \mathrm{C}$ mother alloy and sponge titanium were added in the molten alloy after changing Ar into the furnace. The chemical compositions of as-cast specimens are given in
Table 1 Chemical composition of $\mathrm{Fe}-30 \% \mathrm{Cr}$ alloys (mass\%).

\begin{tabular}{cccccc}
\hline & $\mathrm{Cr}$ & $\mathrm{C}$ & $\mathrm{N}$ & $\mathrm{O}$ & $\mathrm{Ti}$ \\
\hline $\mathrm{T} 1$ & 29.4 & 0.011 & 0.001 & 0.003 & 0.094 \\
$\mathrm{~T} 2$ & 29.8 & 0.025 & 0.001 & 0.004 & 0.21 \\
$\mathrm{~T} 3$ & 29.4 & 0.037 & 0.001 & 0.003 & 0.32 \\
$\mathrm{~T} 4$ & 29.3 & 0.071 & 0.001 & 0.002 & 0.60
\end{tabular}

Table 1. $\mathrm{C}$ and $\mathrm{Ti}$ contents were varied from 0.011 to 0.071 mass $\%$, and from 0.094 to 0.60 mass $\%$, respectively. The ratio $\mathrm{Ti} / \mathrm{C}$ was about nine.

Cast round ingots of $50 \mathrm{~mm}$ in diameter were hot forged and hot rolled at $1273 \mathrm{~K}$ down to $7 \mathrm{~mm} \times 13 \mathrm{~mm}$ square bars, shaper-finished to $5 \mathrm{~mm}$ in thickness, and then cold rolled to $0.5 \mathrm{~mm}$ in thickness. Longitudinal tensile specimens having gage sections of $17 \mathrm{~mm}$ long by $3 \mathrm{~mm}$ wide by $0.5 \mathrm{~mm}$ thick were prepared.

Two kinds of heat treatments were selected to obtain different morphology of $\mathrm{Ti}$ carbide precipitates. In the process "SA" (Solution treatment and Aging), cold rolled specimens were solution treated at $1423 \mathrm{~K}$ for $300 \mathrm{~s}$, quenched into iced water, and aged at $1123 \mathrm{~K}$ for $900 \mathrm{~s}$ followed by quenching into iced water. In the process "SFA" (Solution treatment, Furnace cooling, and Aging), cold rolled specimens were solution treated at $1423 \mathrm{~K}$ for $300 \mathrm{~s}$ followed by furnace cooling at a mean cooling rate of $8.8 \times 10^{-2} \mathrm{~K} \cdot \mathrm{s}^{-1}$ to $1123 \mathrm{~K}$, and aged at $1123 \mathrm{~K}$ for $900 \mathrm{~s}$ followed by quenching into iced water.

Tensile tests were carried out at temperatures ranging from $77 \mathrm{~K}$ to room temperature (RT) at a strain rate of $4.9 \times 10^{-4} \mathrm{~s}^{-1}$ using an Instron machine. Microstructures of the specimens, heat treated by the processes SA or SFA were observed by means of a transmission electron microscope (TEM). Thin foils for TEM observations were first mechanically polished to about $200 \mu \mathrm{m}$ thick and then 
electrolytically thinned at $278 \mathrm{~K}$ in a mixed solution of $20 \%$ perchloric acid and $80 \%$ ethanol. A transmission electron microscope (JEM-2000EX) operating at $200 \mathrm{kV}$ was used. The fracture surfaces after tensile tests were observed by means of two scanning electron microscopes (SEM) (Hitachi-Akasi MSM-101 and JSM-6320F).

\section{Results}

\subsection{Microstructures}

Figure 1 shows a typical electron micrograph of the specimen $\mathrm{T} 2(0.025 \% \mathrm{C})$, heat treated by the process $\mathrm{SA}$. Numerous fine spheroidal $\mathrm{Ti}$ carbide precipitates were observed at grain boundaries. Their size was about $0.05 \mu \mathrm{m}$. In the specimens T3 and T4 (which contain above $0.037 \% \mathrm{C}$ ), heat treated by the process $\mathrm{SA}$, Ti carbide precipitates at grain boundaries were observed as in the specimen T2 shown in Fig. 1, and coarse globular Ti carbide particles within the grains were also observed. The size of the coarse globular Ti carbide particles was about $1 \mu \mathrm{m}$.

Figure 2 shows typical electron micrographs of the grain boundary (a) and $\mathrm{Ti}$ carbide (b) in the specimen $\mathrm{T} 2$

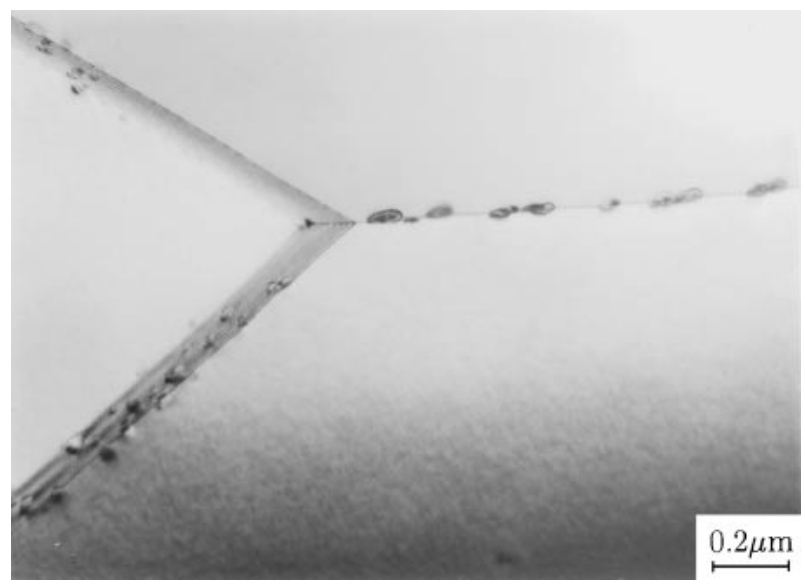

Fig. 1 Transmission electron micrograph of titanium carbides in specimen $\mathrm{T} 2(0.025 \% \mathrm{C})$, heat treated by the process $\mathrm{SA}$.
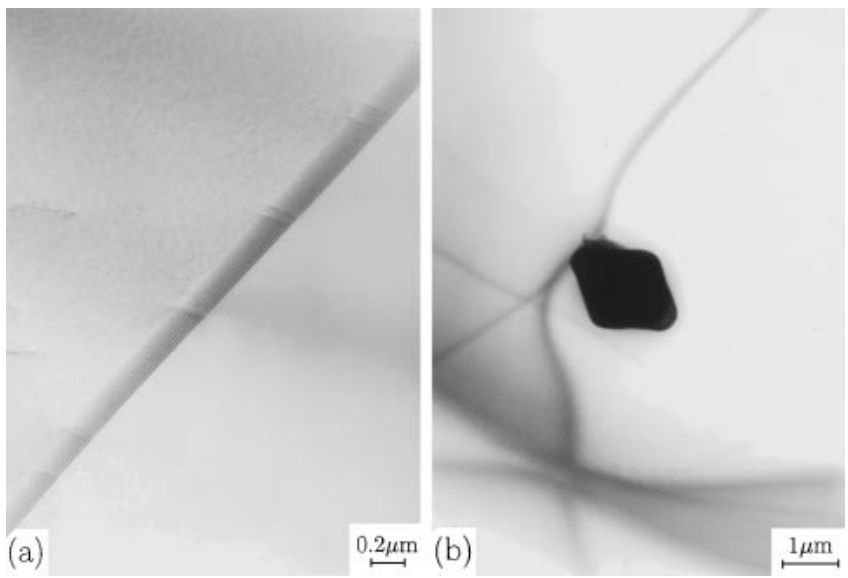

Fig. 2 Transmission electron micrograph of titanium carbides in specimen $\mathrm{T} 2(0.025 \% \mathrm{C})$, heat treated by the process SFA. (a) At grain boundary. (b) Within grain.
$(0.025 \% \mathrm{C})$, heat treated by the process SFA. Majority of coarse globular Ti carbide particles were observed predominantly within the grains, and their size was about $1.5 \mu \mathrm{m}$ (Fig. 2(b)). Fine spheroidal $\mathrm{Ti}$ carbide precipitates were not observed at grain boundaries (Fig. 2(a)). The coarse globular Ti carbide particles were uniformly dispersed in the specimens with below $0.025 \% \mathrm{C}$.

Figure 3 is given an instance of some coarse globular $\mathrm{Ti}$ carbide particles forming a cluster (which is called to clusterlike $\mathrm{Ti}$ carbides) at the grain boundary in the specimen $\mathrm{T} 4$ $(0.071 \% \mathrm{C})$, heat treated by the process SFA. Their size was about $1.5 \mu \mathrm{m}$. Majority of coarse globular Ti carbide particles located within the grains, however the cluster-like $\mathrm{Ti}$ carbides were rarely observed at grain boundaries in the specimens T3 and T4 (which contain above $0.037 \% \mathrm{C}$ ), heat treated by the process SFA. In the case of the process SFA, fine $\mathrm{Ti}$ carbide precipitates at grain boundaries, as shown in Fig. 1 were not observed independent of $\mathrm{C}$ content.

Figure 4 shows an electron micrograph of the specimen T4 $(0.071 \% \mathrm{C})$, heat treated by the process SFA. Some coarse Ti carbide particles on the wavy grain boundary were observed. This phenomenon suggests that grain boundary migration occurred during furnace cooling from 1423 to $1123 \mathrm{~K}$, and

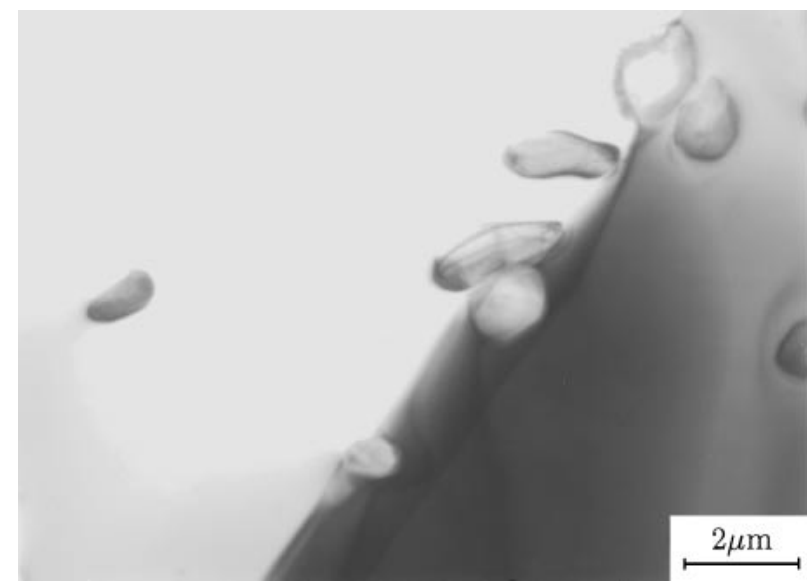

Fig. 3 Transmission electron micrograph of titanium carbides in specimen $\mathrm{T} 4(0.071 \% \mathrm{C})$, heat treated by the process SFA.

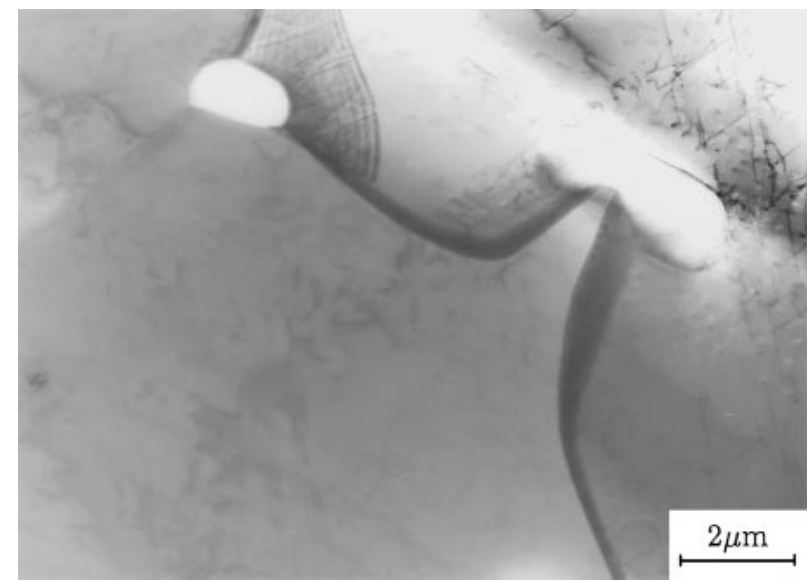

Fig. 4 Transmission electron micrograph of wavy grain boundary in specimen T4 $(0.071 \% \mathrm{C})$, heat treated by the process SFA. 
that the grain boundary was pinned by some coarse Ti carbide particles. Therefore, it should be considered that the clusterlike Ti carbides at grain boundaries shown in Fig. 3 were produced during grain boundary migration.

Despite the fairly similar heat treating temperatures, the differences between the microstructures produced by the two processes remarkably appeared in the location, number and size of the Ti carbide precipitates. That is, the process SA gave rise to grain boundary precipitation of numerous fine $\mathrm{Ti}$ carbides, while the process SFA produced uniformly dispersed coarse globular Ti carbide particles in the specimens with below $0.025 \% \mathrm{C}$ and rarely produced the cluster-like $\mathrm{Ti}$ carbides at the grain boundary in the specimens with above $0.037 \% \mathrm{C}$.

The volume fraction of $\mathrm{Ti}$ carbide precipitates in the specimen, heat treated by the processes SA or SFA was calculated to clarify the relationship between the volume fraction of Ti carbide precipitates and DBTT. The volume fraction of $\mathrm{Ti}$ carbides after quenching from $1123 \mathrm{~K}$ was calculated by using the solubility of $\mathrm{C}$ at $1123 \mathrm{~K}$ and the densities of the matrix and Ti carbide. The solubility of $\mathrm{C}$ at $1123 \mathrm{~K}$ of $\mathrm{Fe}-30 \% \mathrm{Cr}$ alloy (which does not contain $\mathrm{Ti}$ ) has been determined experimentally as $0.002 \% \mathrm{C}^{7}{ }^{7}$ The solubility of $\mathrm{C}$ of $\mathrm{Fe}-30 \% \mathrm{Cr}-\mathrm{Ti}$ alloy is estimated smaller than that of $\mathrm{Fe}-30 \% \mathrm{Cr}$ alloy, because the affinity of $\mathrm{Ti}$ for $\mathrm{C}$ is larger than that of $\mathrm{Cr}$ for $\mathrm{C}$. Therefore the solubility of $\mathrm{C}$ at $1123 \mathrm{~K}$ of $\mathrm{Fe}-30 \% \mathrm{Cr}-\mathrm{Ti}$ alloy is estimated to negligible small. The densities of the matrix and Ti carbide are $7.7 \mathrm{Mg} / \mathrm{m}^{3}$ and $4.9 \mathrm{Mg} / \mathrm{m}^{3}$, respectively. ${ }^{7,10}$ )

Grain size measurement of the specimens after two heat treatment processes was carried out on the etched specimens. In the specimens $\mathrm{T} 1, \mathrm{~T} 2, \mathrm{~T} 3$ and $\mathrm{T} 4$ (which contain from 0.011 to $0.071 \% \mathrm{C}$ ), heat treated by the process SA, their grain size decreased from 125 to $80 \mu \mathrm{m}$ with increasing $\mathrm{C}$ content. In those, heat treated by the process SFA, their grain size decreased from 135 to $82 \mu \mathrm{m}$ with increasing C content. Variations in their grain size between the processes SA and SFA were scarcely recognized.

\subsection{Tensile tests}

In the specimens $\mathrm{T} 1, \mathrm{~T} 2, \mathrm{~T} 3$ and $\mathrm{T} 4$ (which contain from 0.011 to $0.071 \% \mathrm{C}$ ), heat treated by the process $\mathrm{SA}$, their lower yield stress at RT increased from 242 to $268 \mathrm{MPa}$ with increasing $\mathrm{C}$ content. In those, heat treated by the process SFA, their lower yield stress at RT increased from 221 to $266 \mathrm{MPa}$ with increasing $\mathrm{C}$ content. The variations in their lower yield stress between the processes SA and SFA were scarcely recognized.

Figures 5, 6 and 7 illustrate the change in the RA of the specimens $\mathrm{T} 1(0.011 \% \mathrm{C}), \mathrm{T} 3(0.037 \% \mathrm{C})$ and $\mathrm{T} 4(0.071 \% \mathrm{C})$ in tensile tests conducted at temperatures ranging from $77 \mathrm{~K}$ to RT respectively. Microfractographic examinations have been carried out on fractured specimens. Marks D, B, and IG in these figures indicate fracture appearance. Further details will be described later.

In the specimen $\mathrm{T} 1(0.011 \% \mathrm{C})$, heat treated by the process SA (open diamonds in Fig. 5), the RA remained unchanged in the temperatures above $200 \mathrm{~K}$. The RA at $153 \mathrm{~K}$ was slightly lower than that at $200 \mathrm{~K}$, and then the RA decreased to zero at $77 \mathrm{~K}$. On the other hand, the RA for the specimen

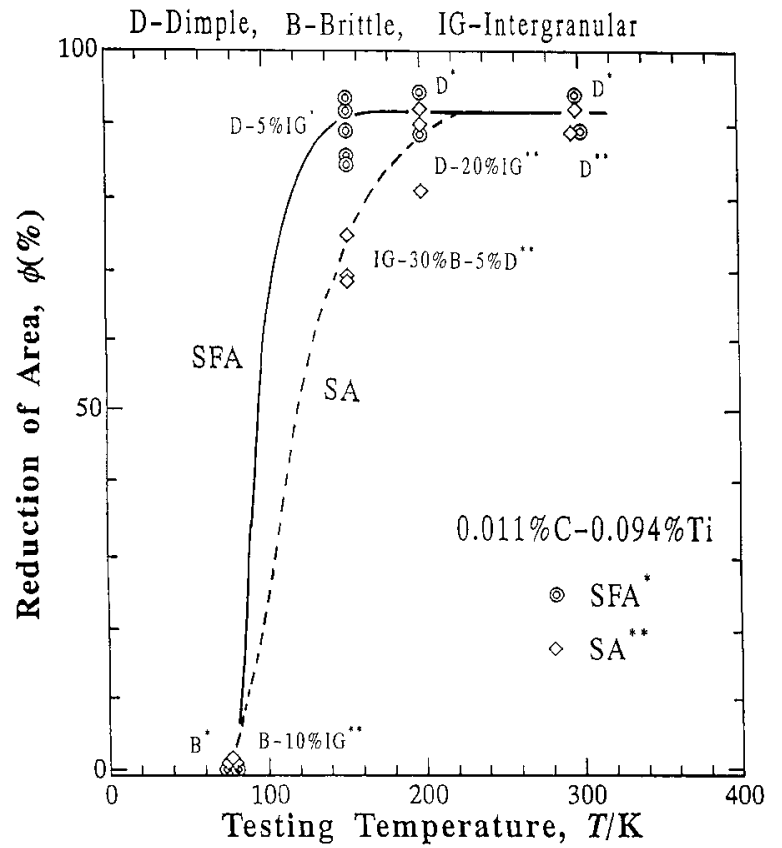

Fig. 5 Relation between reduction of area and testing temperature for specimen $\mathrm{T} 1(0.011 \% \mathrm{C})$, heat treated by the processes SA or SFA. *-SFA. **-SA.

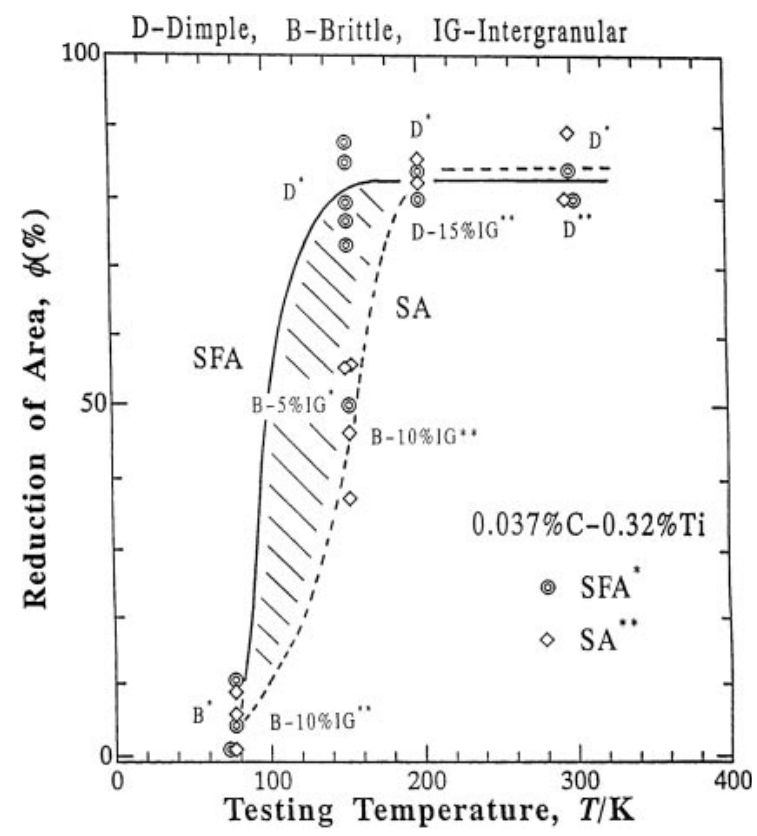

Fig. 6 Relation between reduction of area and testing temperature for specimen T3 $(0.037 \% \mathrm{C})$, heat treated by the processes SA or SFA. *-SFA. **-SA.

T1 $(0.011 \% \mathrm{C})$, heat treated by the process SFA (open double circles in Fig. 5) remained unchanged in the temperatures between RT and $153 \mathrm{~K}$, and then rapidly decreased to zero at $77 \mathrm{~K}$. The DBTT were defined at the point where RA was equal to one-half of the upper shelf in RA. The DBTT for the specimen $\mathrm{T} 1(0.011 \% \mathrm{C})$, heat treated by the process SFA was lower than that for specimen $\mathrm{T} 1(0.011 \% \mathrm{C})$, heat treated by the process SA. 


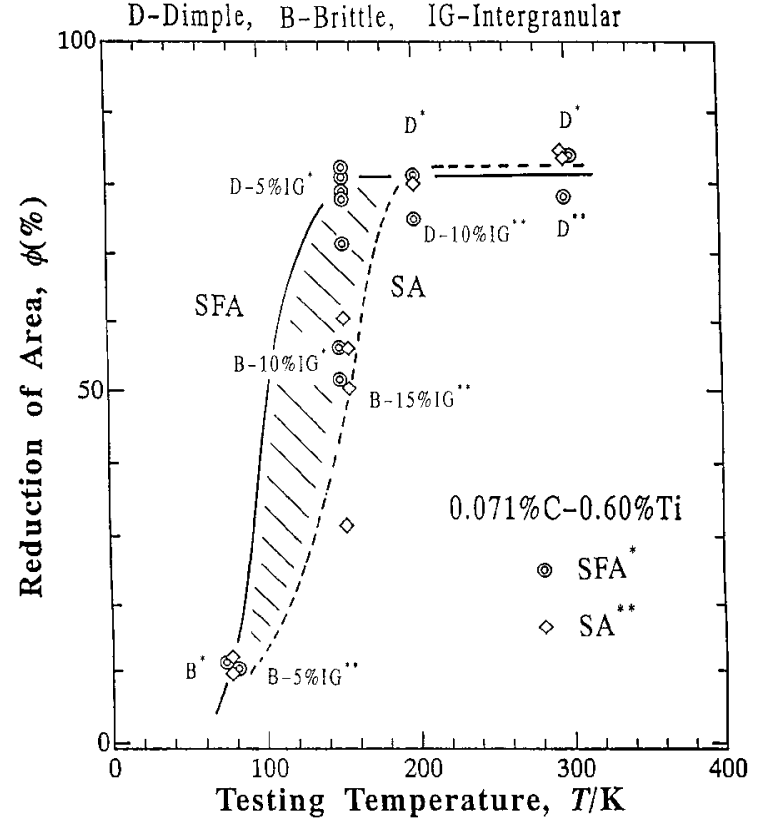

Fig. 7 Relation between reduction of area and testing temperature for specimen T4 $(0.071 \% \mathrm{C})$, heat treated by the processes SA or SFA. *-SFA. **-SA.

The RA for the specimen T3 $(0.037 \% \mathrm{C})$, heat treated by the processes SA or SFA (Fig. 6) showed similar behavior to that for specimen $\mathrm{T} 4(0.071 \% \mathrm{C})$, heat treated by the processes SA or SFA (Fig. 7) in the temperatures between RT and $77 \mathrm{~K}$, respectively. The RA for the specimen T3 $(0.037 \% \mathrm{C})$, heat treated by the process SA remained unchanged in the temperatures above $200 \mathrm{~K}$. The RA at $153 \mathrm{~K}$ was lower than that at $200 \mathrm{~K}$, and then that decreased to zero at $77 \mathrm{~K}$. The DBTT for the specimen T3 $(0.037 \% \mathrm{C})$ was higher than that for the specimen $\mathrm{T} 1(0.011 \% \mathrm{C})$, heat treated by the process SA. The RA for the specimen T3 $(0.037 \% \mathrm{C})$, heat treated by the process SFA remained unchanged in the temperatures above $200 \mathrm{~K}$. The RA values at $153 \mathrm{~K}$ scattered suddenly. Majority of RA values remained unchanged showing the values with above $80 \%$, but the lowest RA value was similar to that for the specimen T3 $(0.037 \% \mathrm{C})$, heat treated by the process SA. The RA for the specimen T4 $(0.071 \% \mathrm{C})$, heat treated by the process SFA (Fig. 7) also scattered at $153 \mathrm{~K}$, while the RA values for the specimens $\mathrm{T} 1$ $(0.011 \% \mathrm{C})$ and $\mathrm{T} 2(0.025 \% \mathrm{C})$, heat treated by the process SFA did not scatter either at same temperature.

The relationship between the RA and morphology of Ti carbide precipitates is summarized as follows. (1) The DBTT for the specimen containing numerous fine $\mathrm{Ti}$ carbide precipitates at grain boundaries was higher than that for the specimen containing uniformly dispersed coarse globular $\mathrm{Ti}$ carbide particles. (2) The cluster-like coarse globular $\mathrm{Ti}$ carbides at grain boundaries caused a scatter band of the DBTT.

Marks D, B, and IG in Figs. 5, 6 and 7 indicate that fracture appearance is principally of dimple fracture-type (D), of brittle fracture-type (B) such as cleavage and quasicleavage fracture, and of intergranular fracture-type (IG), respectively. D-IG indicates the coexistence of dimple-type and intergranular-type. Similarly, the coexistence of brittle- type and intergranular-type is represented by B-IG. The number prior to IG indicates the ratio of intergranular fracture to total fracture area.

In the specimen $\mathrm{T} 1(0.011 \% \mathrm{C})$, heat treated by the process SA, the fracture mode at RT was typically of dimple-type, and that at $200 \mathrm{~K}$ was of dimple fracture containing ductile intergranular fracture. ${ }^{11)}$ In the fracture mode at $153 \mathrm{~K}$, the ductile intergranular fracture, brittle fracrure and dimple fracture were recognized to coexist together. The fracture mode at $77 \mathrm{~K}$ was of brittle fracture containing brittle intergranular fracture. ${ }^{11)}$ On the other hand, in the specimen T1 $(0.011 \% \mathrm{C})$, heat treated by the process SFA the fracture modes in the temperatures above $200 \mathrm{~K}$ were typically of dimple-type, and that at $153 \mathrm{~K}$ is of dimple fracture containing a small part of ductile intergranular fracture. That at $77 \mathrm{~K}$ was of brittle fracture.

The fracture mode of the specimen T3 $(0.037 \% \mathrm{C})$, heat treated by the process SA was similar to that of the specimen $\mathrm{T} 4(0.071 \% \mathrm{C})$, heat treated by the process $\mathrm{SA}$, in the temperatures between RT and $77 \mathrm{~K}$. The fracture mode of the former specimen is described. That at RT was typically of dimple-type, and that at $200 \mathrm{~K}$ was of dimple fracture containing ductile intergranular fracture. That at both 153 and $77 \mathrm{~K}$ was of brittle fracture containing brittle intergranular fracture.

On the whole, the numerous fine grain boundary Ti carbide precipitates bring about the increase in the amount of intergranularly fractured surface in dimple and brittle fracture more than the uniformly dispersed coarse globular Ti carbide particles.

Figure 8 shows a scanning electron micrograph of the fracture surface observed in the specimen $\mathrm{T} 1(0.011 \% \mathrm{C})$, heat treated by the process SA and tensile tested at $153 \mathrm{~K}$. The brittle fracture and brittle intergranular fracture are recognized to coexist together, and the river pattern also appears.

Figure 9 gives high magnification details of the brittle intergranular fracture surface observed in the specimen $\mathrm{T} 3$ $(0.037 \% \mathrm{C})$, heat treated by the process SA and tensile tested at $153 \mathrm{~K}$. The numerous fine Ti carbide precipitates corre-

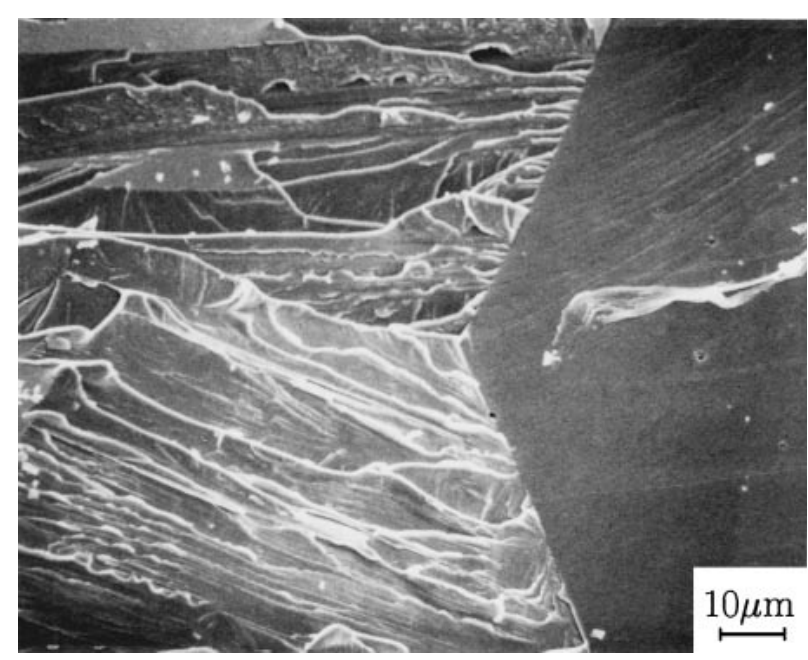

Fig. 8 Scanning electron micrograph of specimen T1 $(0.011 \% \mathrm{C})$, heat treated by the process SA and tensile fractured at $153 \mathrm{~K}$. 


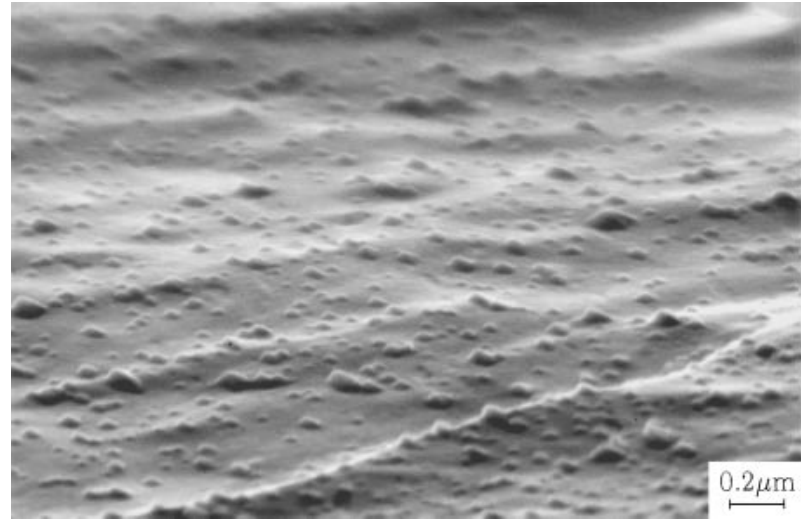

Fig. 9 Scanning electron micrograph showing numerous fine grain boundary $\mathrm{Ti}$ carbide precipitates on intergranular fracture surface of specimen $\mathrm{T} 3(0.037 \% \mathrm{C})$, heat treated by the process $\mathrm{SA}$ and tensile fractured at $153 \mathrm{~K}$.

sponding to Fig. 1 are recognized on the brittle intergranular fracture surface. Convex surfaces of traces of the Ti carbide precipitates and concave those are not mixed in Fig. 9 but only the former is recognized.

The fracture mode of the specimen T3 $(0.037 \% \mathrm{C})$, heat treated by the process SFA was similar to that of the specimen $\mathrm{T} 4(0.071 \% \mathrm{C})$, heat treated by the process SFA, in the temperatures between RT and $77 \mathrm{~K}$. The fracture mode of the latter specimen is described. That in the temperatures above $200 \mathrm{~K}$ was typically of dimple-type, and that at $153 \mathrm{~K}$ presented two types of fracture modes, namely dimple-type and brittle-type. That is, the fracture mode of the specimen showing the higher RA value was of dimple fracture containing a small part of ductile intergranular fracture and that of the specimen showing the lower RA value was of brittle fracture containing brittle intergranular fracture. The fracture mode at $77 \mathrm{~K}$ was of brittle fracture.

Figure 10 shows the scanning electron micrograph of the fracture surface observed in the specimen $\mathrm{T} 4(0.071 \% \mathrm{C})$, heat treated by the process SFA, tensile tested at $153 \mathrm{~K}$, and showing lower RA value. The brittle fracture and brittle intergranular fracture are recognized to coexist together in this figure. The cluster-like Ti carbides were observed on the

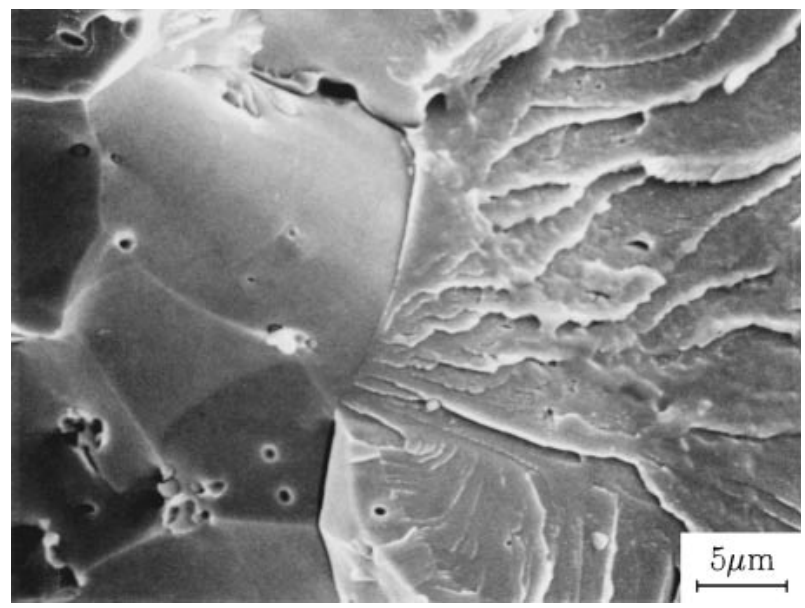

Fig. 10 Scanning electron micrograph of specimen $\mathrm{T} 7(0.071 \% \mathrm{C})$, heat treated by the process SFA and tensile fractured at $153 \mathrm{~K}$.

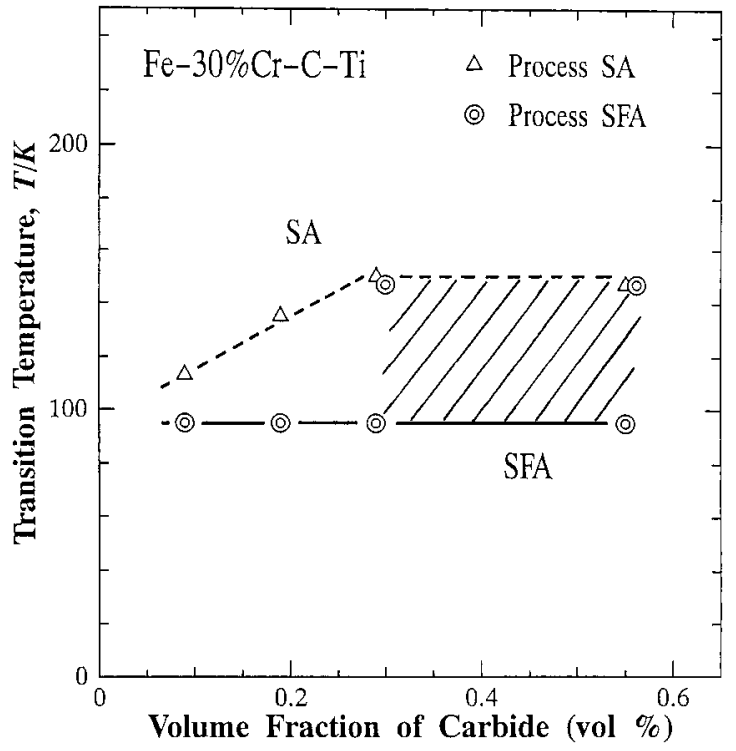

Fig. 11 Relation between the volume fraction of titanium carbide and transition temperature in $\mathrm{Fe}-30 \% \mathrm{Cr}-\mathrm{C}-\mathrm{Ti}$ alloys, heat treated by the processes SA or SFA.

brittle intergranular fracture surface. The river pattern also appears in this figure.

Figure 11 shows the relation between the DBTT and calculated volume fraction of $\mathrm{Ti}$ carbides in a series of $\mathrm{C}$ containing alloys. In the case of the process SA (open triangles) the DBTT increased with increasing Ti carbide up to $0.3 \mathrm{vol} \%$ of $\mathrm{Ti}$ carbide and then it remained unchanged over 0.3 vol $\%$ of Ti carbide. On the other hand in the case of the process SFA (open double circles), the DBTT did not increase with increasing Ti carbide below $0.2 \mathrm{vol} \%$ of $\mathrm{Ti}$ carbide, while it scattered above 0.3 vol\% of Ti carbide. It is obvious that numerous fine carbides on grain boundaries caused the increase in the DBTT more than the uniformly dispersed coarse globular carbides below 0.2 vol\% of $\mathrm{Ti}$ carbide.

\section{Discussion}

The brittle fracture mechanism in the case of the process SA is discussed. In general, it is well known that the appearance of the river pattern is brought about by the movement of a cleavage crack across a grain boundary and a subgrain boundary. ${ }^{12,13)}$ However, the photograph in Fig. 8 shows that the appearance of the river pattern may be brought about by the intergranular fracture crack, and suggests a strong possibility that the microcrack for brittle fracture is initiated by the intergranular fracture crack. This present intergranular fracture shown in Fig. 8 may be caused by the decohesion at the interfaces between the matrix and many $\mathrm{Ti}$ carbide precipitates at grain boundaries, since the author proposed that such decohesion may be caused by a dislocation pile-up at the $\mathrm{Cr}$ carbide and the $\mathrm{Cr}$ nitride precipitates at grain boundaries. 8,11 )

Next, the specimens $\mathrm{T} 3$ and $\mathrm{T} 4$ (which contain above $0.037 \% \mathrm{C}$ ), heat treated by the process SFA and fractured at $153 \mathrm{~K}$ showed two types of fracture modes which were of ductile dimple-type and brittle fracture-type. In spite of 
absence of numerous fine $\mathrm{Ti}$ carbide precipitates at grain boundaries in those specimens, the brittle fracture occurred. The photograph shown in Fig. 10 also suggests the strong possibility that the microcrack for brittle fracture is initiated by the intergranular fracture crack, since the appearance of the river pattern may be brought about by the intergranular fracture. This present intergranular fracture shown in Fig. 10 may be also caused by the decohesion at the interfaces between the matrix and cluster-like coarse globular Ti carbides at grain boundaries. It is considered that when a plane axis direction of the grain boundary surface containing the cluster-like $\mathrm{Ti}$ carbides is nearly at right angles to the plane axis direction of maximum shear stress against the tensile stress direction, ${ }^{14)}$ the brittle fracture may be caused by such brittle intergranular fracture.

In determining a heat treatment condition for the lower DBTT, we must keep in mind to obtain a microstructure in which second phase particles are as possible as dispersed within the grains.

\section{Conclusions}

The effect of the morphology of Ti carbide precipitates on the ductility of 30 mass $\% \mathrm{Cr}$ ferritic steels containing $\mathrm{C}$ and $\mathrm{Ti}$ has been investigated. The different types of the morphology of $\mathrm{Ti}$ carbide precipitates were obtained by two kinds of heat treatment processes. Tensile tests were carried out at temperatures ranging from $77 \mathrm{~K}$ to $\mathrm{RT}$. The tensile ductility was evaluated by transition temperatures in RA.

The results obtained are summarized as follows:

(1) Aging after water quenching from the solution treating temperature gave rise to grain boundary precipitation of numerous fine Ti carbides, whereas furnace cooling from the solution treating temperature to the aging temperature produced uniformly dispersed coarse globular Ti carbide particles in the specimens with below $0.025 \% \mathrm{C}$, and also produced cluster-like coarse globular Ti carbides at grain boundaries in the specimens with above $0.037 \% \mathrm{C}$.
(2) The DBTT for the specimen containing uniformly dispersed coarse globular Ti carbide particles is lower than that for the specimen containing numerous fine grain boundary $\mathrm{Ti}$ carbide precipitates.

(3) The cluster-like coarse globular Ti carbides at grain boundaries caused the scatter band of the DBTT.

(4) Initiation of microcracks for brittle fracture is considered to be caused by the intergranular fracture which is promoted by the decohesion at the interface between the matrix and many grain boundary $\mathrm{Ti}$ carbide precipitates and by the decohesion at the interface between the matrix and cluster-like globular Ti carbides at grain boundaries.

\section{Acknowledgments}

The author wishes to thank their colleagues at Technical Services Division of Institute for Materials Research, Tohoku University, for their experimental cooperation.

\section{REFERENCES}

1) W. O. Binder and H. R. Spenderow, Jr: Trans. ASM 43 (1951) 759_ 772.

2) H. Spitzer: Stahl Eisen 92 (1972) 994-1002.

3) A. Plumtee and R. Gullberg: J. Test. Eval. 2 (1974) 331-336.

4) T. Ototani, K. Yachi, Y. Kataura and T. Fukuda: Trans. Iron Stell Inst. Jpn. 15 (1975) 646-655.

5) A. Plumtee and R. Gullberg: Metall. Trans. 7A (1976) 1451-1458.

6) J. F. Grubb and R. N. Wright: Metall. Trans. 10A (1979) 1247-1255.

7) T. Fukuda, Y. Kataura and T. Ototani: J. Japan Inst. Metals 54 (1990) 93-100.

8) T. Fukuda, H. Suenaga and M. Tanino: J. Japan Inst. Metals 59 (1995) 437-446.

9) T. Fukuda: J. Japan Inst. Metals 65 (2001) 151-154.

10) Japan Inst. Metals: Kinzoku Deita Bukku, (1974) pp. 127-127.

11) T. Fukuda and M. Tanino: Mater. Trans., JIM 40 (1999) 1396-1401.

12) J. J. Gilman: Trans. Met. Soc. AIME 212 (1958) 310-315.

13) G. Henry and L. Roesch: Translated by H. Funakubo, Tetsu-to-Hagané 57 (1971) 57-73.

14) A. W. Thompson and J. F. Knott: Metall. Trans. 24A (1993) 523-534. 